SANT'ANA, D.S. et al. Aspectos gerais sobre a circovirose suína. PUBVET, Londrina, V. 5, N. 10, Ed. 157, Art. 1059, 2011.

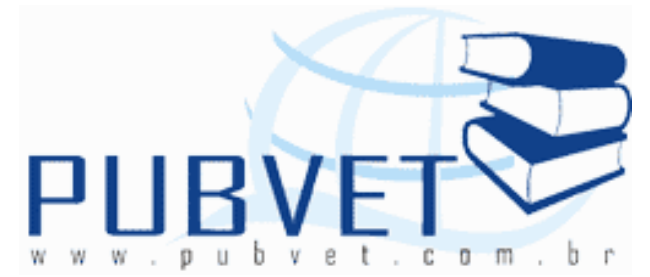

PUBVET, Publicações em Medicina Veterinária e Zootecnia.

\title{
Aspectos gerais sobre a circovirose suína
}

Driele Schneidereit Sant'ana ${ }^{1}$; Millene Torres de Oliveira ${ }^{1}$; Camila Motta Marin Bernardi²; Leonardo Gomes Carrazzaㄹ; Thaís Gomes Carrazza³

1 - Mestrando do Programa de Pós-Graduação em Ciências Veterinárias da Universidade Federal de Uberlândia - UFU.

2 - Professora Msc. da Faculdade de Ciências Agrárias de Andradina-SP

3 - Graduanda do curso de Medicina Veterinária da Universidade Federal de Uberlândia - UFU.

\section{Resumo}

A Circovirose suína causa um dos maiores prejuízos na criação e exploração de suínos no Brasil e no mundo. A infecção generalizada envolve vários sistemas corporais. O resultado final é um atraso significativo no crescimento e refugagem de leitões afetados. É uma doença caracterizada por depressão, perda progressiva de peso, taquipnéia, dispnéia, icterícia, palidez cutânea e diarréia em leitões de cinco á 13 semanas de idade. Na necropsia, os achados mais importantes são o aumento de volume de linfonodos e pulmão nãocolapsado, com áreas consolidadas, principalmente nos lobos craniais e porção anterior dos lobos médios. O diagnóstico da infecção baseia-se na análise de sintomatologia e no isolamento do vírus, na identificação de antígenos ou do genoma viral em animais suspeitos a partir de lesões macroscópicas e 
SANT'ANA, D.S. et al. Aspectos gerais sobre a circovirose suína. PUBVET, Londrina, V. 5, N. 10, Ed. 157, Art. 1059, 2011.

microscópicas, alterações hematológicas e bioquímicas. O objetivo desta revisão foi fazer um levantamento sobre a Circovirose suína.

Palavras-chave: Circovírus Suíno Tipo 2, Patologia, Síndrome Multissistêmica da Definhamento Suíno (SMDS) e Suínos.

\section{Abstract}

The porcine circovirus causes one of the largest damage in the raising and exploration of swines in Brazil and all over the world. The generalized infection involves various body systems. The end result is a significant delay in growth and culling of affected piglets. It is a disease characterized by depression, progressive weight loss, tachypnea, dysponea, jaundice, skin paleness and diarrhea in pigles from five to five to 13 weeks of age. At necropsy, the most important findings are the increased volume of lymph nodes and not collapsed lungs with consolidated areas, mainly in the cranial lobes and the anterior portion of the medium lobes. The infection diagnosis is based on the symptomatology analysis and the isolation of the virus, in the identification of antigens or the viral genoma in suspected animals, from macroscopic and microscopic lesions, hematological and biochemical anormalities. The objective of this review was to do a survey about Circovirosis swine.

Keywords: Multisystemic Wasting Syndrome (MWS), Pathology, Porcine Circovirus Type 2 and Swine.

\section{INTRODUÇÃO}

A circovirose suína é um conjunto de síndromes causadas pela infecção do Circovírus Suíno Tipo 2 (PCV2). Esta doença tem causado grandes prejuízos e perdas econômicas em todas as granjas do Brasil e tem sido a mais pesquisada na suinocultura mundial. Está relacionada com outras doenças como a Síndrome da Dermatite e Nefropatia suína (SDNS), Síndrome Multisistêmica do Definhamento dos Suínos (SMDS), Falhas Reprodutivas, Pneumonias Associadas ao Complexo Respiratório Suíno (SRDC), enterites e 
SANT'ANA, D.S. et al. Aspectos gerais sobre a circovirose suína. PUBVET, Londrina, V. 5, N. 10, Ed. 157, Art. 1059, 2011.

tumores congênitos. Dentre estas, a SMDS é a mais freqüente, quando as falhas reprodutivas são causadas pelo PVC2, caracterizando aumento na ocorrência de abortos natimortos, mumificados e nascimento de leitões fracos 2 .

Em 2005, baseados em dados de empresas integradoras estimou-se um impacto econômico anual de 33 milhões de reais apenas para a região Sul do Brasil.

A partir desta revisão objetiva-se fazer um levantamento dos aspectos gerais que envolvem a Circovirose Suína e o impacto econômico causado por ela.

\section{REVISÃO DE LITERATURA}

O circovírus dos suínos ou circovírus porcino (PCV), foi inicialmente detectado como contaminante de cultivos celulares de células de rim de suínos da linhagem PK-15. O vírus isolado destas células (denominados "PCV PK-15") possui um genoma de 760 nucleotídeos. Com base na sua composição e morfologia, o PCV foi classificado em uma nova família de vírus animais, denominada Circoviridae, que são vírus pequenos com cerca de $17 \mathrm{~nm}$, não envelopados, com DNA circular de fita simples, é um dos menores entre outros vírus que acometem os animais ${ }^{10}$. O Circovírus resiste à inativação quando exposto a ambiente ácido $(\mathrm{pH}-3)$, a clorofórmio, a temperaturas entre 56 e $70^{\circ} \mathrm{C}$, ao congelamento, à luz ultravioleta e a desinfetantes. O agente permanece estável em fezes e secreções respiratórias ${ }^{7}$.

São conhecidos dois tipos de PCV: o Circovírus tipo 1 (PCV1) que é apatogênico para suínos, e o Circovírus suíno tipo 2 (PCV2), associado a SMDS e SDNS. O PCV1 infecta suínos no mundo inteiro, mas não causa a doença. Em um estudo realizado na Alemanha e citado por Zanella (2008), 60\% do soro de suínos no abate continham anticorpos para PCV1. Nesse estudo, foram realizadas infecções experimentais em leitões soronegativos e detectou-se a presença do vírus nas fezes e de muco nasal de leitões com ataxia congênita e 
SANT'ANA, D.S. et al. Aspectos gerais sobre a circovirose suína. PUBVET, Londrina, V. 5, N. 10, Ed. 157, Art. 1059, 2011.

esta transmissão vertical foi reproduzida. Porcas prenhas foram inoculadas com este isolado e a leitegada ao nascer apresentou tremores, porém o tipo de PCV não foi caracterizado ${ }^{10}$.

Em relação ao PCV2, ainda estão sendo concluídos estudos sobre a soroprevalência, modo de transmissão, excreção viral e tropismo do vírus. Um estudo Canadense indicou que anticorpos para PCV2 estão presentes em animais de rebanhos em sistemas de produção final, unidades de engorda e também de criações de fundo de quintal, e que a soroconversão ocorre três a quatro semanas após o desmame ${ }^{2}$.

A enfermidade foi conhecida pela primeira vez no Canadá em 1991, e desde então, tem sido descrita em vários países. No Brasil, o PCV2 associado á SMDS foi diagnosticado pela primeira vez em 2002, nos estados de Santa Catarina e Rio Grande do Sul, foi descrita em $2003^{10}$.

Acredita-se que a transmissão do PCV2 ocorra de forma vertical e horizontal. A associação do PCV2 com abortos e natimortos indica que a transmissão transplacentária também pode ser um fator importante, caso matrizes soronegativas estiverem infectadas ${ }^{7}$. Instalações, equipamentos e fômites são fatores prováveis na transmissão horizontal do vírus. Fatores de risco causadores de estresse, como densidade elevada, baixa qualidade do ar, água e ração, mistura de lotes com procedência e idades diferentes e presença de enfermidades concomitantes, podem intensificar as manifestações clínicas e favorecer o desenvolvimento da doença ${ }^{10}$. O fato do vírus também ser encontrado no sêmen pode colaborar para uma rápida disseminação. O DNA de PCV2 já foi detectado por nested-PCR (reação em cadeia polimerase interna), em sêmen de machos suínos em Centrais de Inseminação Artificial (CIA) no sul do Brasil ${ }^{9}$.

Muito se debate acerca de como o PCV2 entra nas células. Duas hipóteses têm sido levantadas. Através da fagocitose de outras células infectadas (endocitose) ou pela possível existência de um receptor para PCV2 na superfície de macrófagos. Esse receptor, porem até o momento, não foi 
SANT'ANA, D.S. et al. Aspectos gerais sobre a circovirose suína. PUBVET, Londrina, V. 5, N. 10, Ed. 157, Art. 1059, 2011.

identificado. Talvez a presença de PCV2 possa ocorrer por ambos os mecanismos ${ }^{1}$.

A Síndrome Multisistêmica do Definhamento dos Suínos (SMDS) é uma das síndromes mais importantes causada pelo PCV2, sendo observada em suínos entre 4 a 14 semanas. A morbidade e a mortalidade em suínos desmamados mostram-se superiores a $50 \%$ em algumas criações. Pode ser observada alta mortalidade em suínos com sintomas, porém a morbidade geralmente é baixa ${ }^{5}$.

A SMDS causa elevada mortalidade em suínos nas fases de creche, crescimento e terminação. Nas manifestações clínicas, os animais afetados pela SMDS apresentam perda de peso, emaciação, taquipnéia, dispnéia, tosse, respiração ofegante e pela boca, icterícia, diarréia, aumento de linfonodos (principalmente inguinais e mesentéricos), lesões de pele nas extremidades das orelhas, nos membros posteriores e na região ventrocaudal, representadas por pápulas e placas avermelhadas, distúrbios do sistema nervoso: caracterizados por tremores, convulsões, desordens locomotoras e prostação. Alguns autores correlacionam o PCV2 a desordens reprodutivas e aborto e, também, até a morte súbita foram relatados ${ }^{11}$.

As lesões macroscópicas mais importantes incluem linfoadenomegalia (inguinais, submandibulares, mesentéricos e mediastínicos sendo a mais freqüentes), hipotrofia de timo e pulmão não colabados, ás vezes com pequenas áreas disseminadas de hepatização vermelha ${ }^{3}$. Entretanto as lesões nem sempre estão presentes e, portanto, não podem ser utilizadas como único indicador da SMDS. O fígado de animais ictéricos também pode apresentar atrofia e áreas descoloradas ou pontos brancacentos. Pontos multifocais brancacentos ou difusos podem ser vistos na superfície e parênquima dos rins, porém nos casos de SDMS, a atrofia renal é apenas discreta ${ }^{2}$.

$\mathrm{Na}$ pele são observadas manchas avermelhadas e arredondadas de diferentes tamanhos observadas em alguns casos. Muitos animais com sinais de definhamento apresentam, também, úlcera gastro-esofágica, responsável 
SANT'ANA, D.S. et al. Aspectos gerais sobre a circovirose suína. PUBVET, Londrina, V. 5, N. 10, Ed. 157, Art. 1059, 2011.

por hemorragias intensas e pelo sinal de palidez da pele e mucosa. Várias outras lesões, como polisserosites, consolidação pulmonar e colite podem ser encontradas, dependendo das infecções secundárias observadas a campo ${ }^{2}$. Porém, sabe-se que o PCV2 pode provocar pneumonia intersticial e enterite por ação do vírus. No Brasil, as polisserosites e as colites são as lesões concomitantes mais freqüentes ${ }^{8}$ (Tabela 1 ).

TABELA 1. Freqüência das lesões macroscópicas observadas em 396 suínos infectados com PCV2.

\begin{tabular}{lcl}
\hline Achados macroscópicos & Freqüência & \% \\
\hline Emaciação, espinha dorsal marcada & 318 & 80,30 \\
Icterícia & 12 & 3,03 \\
Linfoadenomegalia & 209 & 52,78 \\
Necrose de linfonodo & 9 & 2,27 \\
Ausência de colabamento pulmonar & 225 & 64,39 \\
\hline Consolidação pulmonar crânio-ventral & 235 & 59,34 \\
Pneumonia necrotizante & 8 & 2,02 \\
Atrofia serosa de gordura pericárdica & 90 & 22,73 \\
Úlcera gástrica da pars oesafhagea & 113 & 28,54 \\
Rins com manchas esbranquiçadas & 73 & 18,43 \\
Atrofia hepática & 13 & 3,28 \\
Hepatomegalia & 2 & 0,51 \\
Fezes pastosas ou líquidas & 44 & 11,11 \\
Colite fibrino-necrozante & 13 & 3,28 \\
Serosite (mono ou poliserosite) & 99 & 25,00 \\
\hline
\end{tabular}

Fonte: Sobestiansky, et al., 2002. 
SANT'ANA, D.S. et al. Aspectos gerais sobre a circovirose suína. PUBVET, Londrina, V. 5, N. 10, Ed. 157, Art. 1059, 2011.

As lesões histopatólogicas atribuídas a SMDS são observadas em diversos órgãos como pulmão, fígado, intestino, pâncreas, testículo, cérebro, glândulas adrenais e da tireóide, mas são predominantes em órgãos linfóides ${ }^{3}$. Essas lesões consistem em diminuição do número de linfócitos, com presença de corpúsculo de inclusão intracitoplasmáticos, que são encontrados nas áreas dos linfonodos dependentes de células $B$, podendo ocorrer em células dispersas nesse órgão. Essas células são geralmente da linhagem monocítica (macrófagos e células dendriticas).

Observa-se também, lesões com ocorrência e freqüência variável como hepatites, pancreatites, nefrites e pneumonia intersticial nos animais infectados. As características mais consistentes durante 0 exame histopatológico são o aumento de linfonodos, baço e consolidação pulmonar. No coração também são observadas lesões granulomatosa no miocárdio e hidropericárdio ${ }^{4}$.

Ainda não foi totalmente elucida a patogenia do vírus, e quais células alvo o vírus coloniza em alguns tecidos de suínos infectados pela SMDS, e nem o tropismo celular e alterações celulares que a infecção pode causar. A depleção de linfócitos é característica da infecção por PCV2 e da SMDS, porém não se sabe se a morte celular ou apoptose é devido à infecção pelo vírus ou por outros fatores, como a resposta inflamatória em si ${ }^{3}$ (Tabela 2). 
SANT'ANA, D.S. et al. Aspectos gerais sobre a circovirose suína. PUBVET, Londrina, V. 5, N. 10, Ed. 157, Art. 1059, 2011.

TABELA 2. Freqüência das lesões microscópicas observadas em 396 suínos infectados com PCV2.

\begin{tabular}{|c|c|c|}
\hline Achados microscópicos & ência & $\%$ \\
\hline \multicolumn{3}{|l|}{ Tecidos Linfóides: } \\
\hline Depleção linfocitária & 353 & 89,14 \\
\hline Infiltrado inflamatório histiocitária & 305 & 77,02 \\
\hline Corpos de inclusão intracitoplasmáticos & 137 & 34,60 \\
\hline Células gigantes (multinucleadas) & 113 & 28,54 \\
\hline Necrose de coagulação multifocal & 39 & 9,85 \\
\hline \multicolumn{3}{|l|}{ Pulmão: } \\
\hline Pneumonia intersticial & 304 & 76,77 \\
\hline Broncopneumonia catarral-purulenta & 218 & 55,05 \\
\hline Pneumonia necrotizante & 26 & 4,04 \\
\hline \multicolumn{3}{|l|}{ Fígado: * } \\
\hline Grau I & 131 & 33,08 \\
\hline Grau II & 34 & 8,59 \\
\hline Grau III & 8 & 2,02 \\
\hline Grau IV & 5 & 1,26 \\
\hline Total & 178 & 44,95 \\
\hline \multicolumn{3}{|l|}{$\underline{\operatorname{Rim}:}$} \\
\hline Nefrite intersticial & 149 & 37,63 \\
\hline \multicolumn{3}{|l|}{ Cólon: } \\
\hline Colite linfoplasmocitária & 68 & 15,00 \\
\hline Colite fibrino-necrotizante & 17 & 3,79 \\
\hline
\end{tabular}

* Conforme classificação de Jones, et al., 2000.

Fonte: Sobestiansky, et al., 2002. 
SANT'ANA, D.S. et al. Aspectos gerais sobre a circovirose suína. PUBVET, Londrina, V. 5, N. 10, Ed. 157, Art. 1059, 2011.

Nas alterações hematológicas e bioquímicas, o número de linfócitos é significativamente baixo e o de monócitos e neutrófilos fica claramente aumentado, com uma inversão da proporção linfócito/neutrófilo. Por outro lado, não há alteração no número total de leucócitos. Suínos com a SMDS, geralmente tem anemia normocítica hipocrômica, com leve aumento inicial do número de células vermelhas. Essa anemia é resultado do processo inflamatório crônico no qual o sequestro de ferro ocorre no sistema retículoendotelial ${ }^{5}$.

Estudos com suínos necropsiados apresentavam baixo desempenho corporal com estado de caquexia e palidez de mucosas. Linfonodos e baço aumentado de tamanho. Tanto os linfonodos inguinais como os linfonodos mesentéricos apresentaram, em alguns casos, aumento de volume acentuado, difuso com congestão, hemorragia e áreas multifocais coalescentes com conteúdo de aspecto caseoso. Os rins, além de aumento em volume, estavam pálidos e apresentavam pontos brancos de tamanhos variáveis e frequentemente havia pequenos pontos vermelhos, semelhantes à petéquias, distúrbios por toda a zona cortical, pulmões não colapsados com bordas arredondadas e áreas de consolidação, além de edema de septos interlobulares ${ }^{3}$.

O diagnóstico da SMDS pode ser realizado baseado nas combinações entre os sinais clínicos observados, lesões patológicas macro e microscópicas (Tabelas 1 e 2), e na deteç̧ão de antígeno ou ácido nucléico (DNA) de PCV2 nas lesões dos suínos afetados. Dentre os métodos de detecção de anticorpos no soro de suínos, este pode ser realizado por imunofluorescência ou imunoperoxidase indireta, sendo que pode ocorrer reação cruzada entre os antígenos de PCV1 e PCV2, ou pode-se usar a técnica de reação em cadeia da polimerase interna (nested-PCR), verificada pela presença de PCV2 em cortes histológicos e no sêmen de machos suínos ${ }^{9}$ (Tabela 3 ). 
SANT'ANA, D.S. et al. Aspectos gerais sobre a circovirose suína. PUBVET, Londrina, V. 5, N. 10, Ed. 157, Art. 1059, 2011.

TABELA 3. Amostra mais adequadas para o estabelecimento do diagnóstico histopatológico do PCV2

\begin{tabular}{ll}
\hline Tecidos & Características da amostra \\
\hline Linfonodos & Inteiros (incluir vários linfonodos) \\
Amígdala & Inteiros \\
Íleo & Um fragmento de cerca de $5 \mathrm{~cm}$ e aberto \\
Baço & Um fragmento tranversal de cerca de $0,5 \mathrm{~cm}$ de largura \\
Pulmão & Vários fragmentos de cerca de $5 \mathrm{~cm}$ de largura de todo \\
lóbulos & \\
Fígado & Vários fragmentos de cerca de $5 \mathrm{~cm}$ de largura \\
Rim & Um fragmento tranversal de $0,5 \mathrm{~cm}$ de largura \\
\hline
\end{tabular}

Fonte: Sobestiansky, et al., 2002.

A vacinação profilática ideal tem como objetivo a estimulação do sistema imune do hospedeiro para prepará-lo para um encontro com um agente. Além destes aspectos imunológicos gerais, aspectos mais práticos podem ser adicionados, especialmente para vacinas veterinárias.

Embora não sejam ideais em todos os aspectos, algumas vacinas utilizadas hoje em dia podem claramente contribuir no controle ou mesmo à eliminação de certas doenças infecciosas de suínos ${ }^{11}$. Por exemplo, vacinas seguras e, relativamente eficazes estão disponíveis para a febre aftosa (FMD), peste suína clássica (CSF), e Doença de Aujeszky (AD), também chamada de pseudoraiva $(P R)$, mas ainda não para Peste Suína Africana (ASF) e síndrome respiratória e reprodutiva dos suínos (PRRS). Também para a síndrome da refugagem de suínos (Postweanig Multi-systemic Wasting Syndrome - PMWS), causada pelo Cicorvírus porcino 2 (PCV2), vacinas eficazes bem estabelecidas não estão ainda disponível ${ }^{5}$.

Levantamentos estimam que a circovirose custa aos produtores europeus, entre 562 e 900 milhões de euros por ano e, em 2005, cerca de 33 milhões de 
SANT'ANA, D.S. et al. Aspectos gerais sobre a circovirose suína. PUBVET, Londrina, V. 5, N. 10, Ed. 157, Art. 1059, 2011.

reais apenas para a região sul do Brasil e severos surtos ocorrem no mundo todo ${ }^{8}$.

As explosões de SMDS podem ser parcialmente controladas, principalmente através da melhoria das práticas de manejo, oferta de um ambiente confortável aos leitões, evitando situações estressantes, como a transferência de leitões de granjas afetadas para outras sem 0 problema ${ }^{7}$, lavagem e desinfecção das salas após a saída dos leitões para engorda, aquecimento das mesmas algumas horas antes da entrada dos animais e rigoroso controle de temperatura e uso de antibióticos para prevenção das demais doenças ${ }^{9}$.

Entretanto desde outubro de 2004, tornou-se disponível para o controle da Circovirose uma vacina a base de PCV2 inativada destinada a porcas e marrãs, porém essa vacina ainda é objetivo de estudo e não é usada ainda como método profilático contra a Circovirose nas granjas do Brasil ${ }^{10}$.

\section{CONSIDERAÇÕES FINAIS}

A Circovirose Suína é uma doença que causa grandes perdas econômicas devido às mortes, ao declínio das taxas de crescimento e piora na conversão alimentar, levando a uma diminuição da produtividade das granjas de suínos. O PCV2 é um vírus que acomete suínos há muito tempo, porém foi identificado recentemente, sendo objeto de estudo para a suinocultura industrial, bem como seu tropismo, forma de disseminação e controle. Contudo, o manejo correto é fator fundamental para o controle da doença, fornecer ambiente confortável aos leitões, evitar situações estressantes para o animal, diminuir a densidade nos galpões, melhoria da higiene e separação dos animais refugos dos sadios, e posteriormente, eliminação dos animais positivos para a enfermidade, assegurando a eficiente biosegurança na granja, são fatores que favorecem o controle e evitam a disseminação desta síndrome. 
SANT'ANA, D.S. et al. Aspectos gerais sobre a circovirose suína. PUBVET, Londrina, V. 5, N. 10, Ed. 157, Art. 1059, 2011.

\section{REFERÊNCIAS BIBLIOGRÁFICAS}

1. BORDIN, E. L. et al Vacinação de porcas e marrãs contra doenças causadas pelo PCV2. Revista Suinocultura Industrial, no 02, ano 30, 2008. p. 22 - 26.

2. CASTRO, A. M. M. G. et. al, Circuvírus suíno tipo 2 (PCV-2). Arq. Inst. Biol., São Paulo, v.74, n.3, jul./set. de 2007. p. 181-191.

3. CORRÊA, A. M. R. Aspectos clínicos - patológicos associados á circovirose suína no Rio Grande do Sul. Pesquisa Veterinária Brasileira, volume 26, nº1, 2006. p. 13 - 23.

4. JONES T. C. et. al, Patologia Veterinária, 6.ed.São Paulo: Editora Manole, 2000. p. $1159-1162$.

5. RIJSEWIJK, F. Segurança e eficácia, Revista Suinocultura Industrial, Edição 203, no 02, ano 30, 2007. p. $18-27$.

6. SOBESTIANSKY J. Infecção pelo Circovírus. Clínica de Patologia Suína, 2.Ed. Goiânia Editora: ROCA, 1999. p. 199 - 201.

7. SOBESTIANSKY, J. et al., Lesões Macro e Microscópicas. Circovirose suína e Circovirose suíno, 1.Ed. Goiânia, Editora: Pfizer, 2002. p. 17-05.

8. SOBESTIANSKY, J. \& BARCELLOS, D., Circovirose suína. Doenças dos suínos 1.Ed. Goiânia, Editora: Cânone, 2007. p. 213-225.

9. ZANELLA, J. R. C. O papel do macho na epidemiologia da Circovirose. Revista Suinocultura Industrial, Edição 213, no 03, ano 30, 2008. p. 14 - 18.

10. ZANELLA J.R.C. Segurança e eficácia. Revista Suinocultura Industrial, Edição 203, no 02 , ano 30, 2007. p. $14-17$.

11. ZANELLA J.R.C. \& MORÉS N. Perfil sanitário da suinocultura no Brasil, publicado em 2005. Disponível em: <http://www.cnpsa.embrapa.br> Acesso em: 20 de jan. de 2009. 